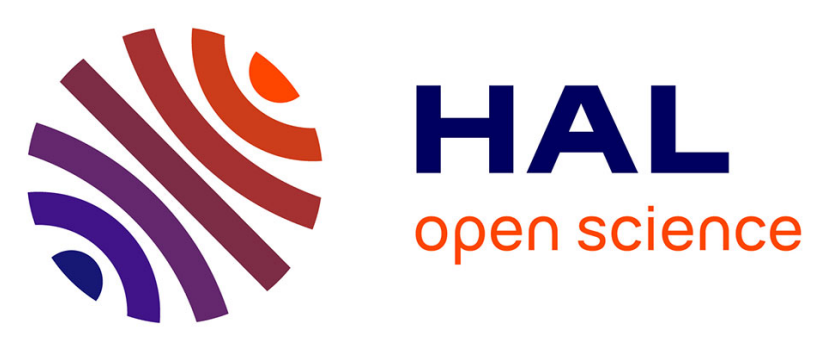

\title{
To a cultural perspective of mixed reality events: a case study of event overflow in operas and concerts in mixed reality
}

Jean-François Lucas, Tracy Cornish, Todd Margolis

\section{- To cite this version:}

Jean-François Lucas, Tracy Cornish, Todd Margolis. To a cultural perspective of mixed reality events: a case study of event overflow in operas and concerts in mixed reality. New Review of Hypermedia and Multimedia, 2012, 18 (4), pp.277-293. halshs-00974362

\section{HAL Id: halshs-00974362 \\ https://shs.hal.science/halshs-00974362}

Submitted on 6 Apr 2014

HAL is a multi-disciplinary open access archive for the deposit and dissemination of scientific research documents, whether they are published or not. The documents may come from teaching and research institutions in France or abroad, or from public or private research centers.
L'archive ouverte pluridisciplinaire HAL, est destinée au dépôt et à la diffusion de documents scientifiques de niveau recherche, publiés ou non, émanant des établissements d'enseignement et de recherche français ou étrangers, des laboratoires publics ou privés. 
Publication details, including instructions for authors and subscription information: http://www.tandfonline.com/loi/tham20

\section{To a cultural perspective of mixed reality events: a case study of event overflow in operas and concerts in mixed reality 2012}

\section{WORKING PAPER}

Thank you to quote and refer to the final version :

Jean-François Lucas , Tracy Cornish \& Todd Margolis (2012): To a cultural perspective of mixed reality events: a case study of event overflow in operas and concerts in mixed reality, New Review of Hypermedia and Multimedia, 18:4, 277-293

To link to this article: http://dx.doi.org/10.1080/13614568.2012.746741

- Jean-François Lucas, Interdisciplinary Center for Human and Social Process Analysis (CIAPHS - EA 2241), Sociology Department, European University of Brittany, Rennes, France

- Tracy Cornish, Center for Research in Computing and the Arts, University California, San Diego, USA

- Todd Margolis, California Institute for Telecommunications and Information Technology, University of California, San Diego, USA

This working paper is available to public in order to publicize the work the authors.

This text is intended for personal and non-commercial uses. It may not be distributed in any way and used for profit.

The final article may be used for research, teaching, and private study purposes. Any substantial or systematic reproduction, redistribution, reselling, loan, sub-licensing, systematic supply, or distribution in any form to anyone is expressly forbidden. Please refer to http://dx.doi.org/10.1080/13614568.2012.746741 


\title{
To a cultural perspective of mixed reality events: a case study of event overflow in operas and concerts in mixed reality
}

\author{
JEAN-FRANCOIS LUCAS(1), TRACY CORNISH(2) and, TODD \\ MARGOLIS(3)
}

(1)Interdisciplinary Center for Human and Social Process Analysis (CIAPHS - EA 2241),Sociology Department, European University of Brittany, Rennes, France

(2)Center for Research in Computing and the Arts, University California, San Diego, USA

(3) California Institute for Telecommunications and Information Technology, University of California, San Diego, USA

Mixed reality defines the sharing of a space-time between the real and the virtual world. The definition of this concept is further extended when virtual worlds such as Second Life+ (SL) are included. Through cultural events such as concerts and operas, we will see that the main goal of these kinds of projects is not simply to offer a video and audio broadcast of these events in the digital dimension. The current challenge is to create interactions between the individuals who are in different shared spaces. By studying the unfolding of these events in its various phases*before, during, and after*we examine the culture of the event. We question how the culture of the event can be transposed in a mixed reality display, and how this kind of event can affect people on both sides of the "membrane" made by the technical configuration. Beyond the alignments and adjustments that we can see between the different individuals involved in these events, we examine more broadly the changes and mutations of the culture of the event in this specific configuration.

Keywords: Mixed reality; Event; Virtual worlds; Overflow; Vectors of affectation

Yes, I believe that there is a multiple people, a people of mutants, a people of potentialities that appears and disappears, that is embodied in social, literary, and musical events ... I think that we're in a period of productivity, proliferation, creation, utterly fabulous revolutions from the viewpoint of this emergence of a people. That's molecular revolution: it isn't a slogan or a program, it's something that I feel, that I live ... (Guattari and Rolnik 2008) 


\section{Introduction}

In this article, we propose to study new forms of experiences which take place in mixed reality and use Second Life + (SL) as an element of its composition. In order to understand the importance of these new forms of expression and sharing events, we will take two examples of cultural projects that have been developed between the city of Rennes (France) and digital sites in Second Life+. The main purpose of this article is to understand if we can see the emergence of new cultural forms during these kinds of events, or if we are simply facing the development of cultural practices that are already established and taken place in different settings and frames of reference. In other words, is mixed reality redefining the practice and culture of some cultural events, or does it just redistribute cultural heritages?

There are many ways to respond to this problematic question. For example, it is possible to question the mediations (Latour 2007) that come into play to understand how the culture of the event as well as the technical side of the device can affect a mixed reality event. But, if we want to understand how mediations can transform an experience in mixed reality, we have first to define what exactly is an event. In this sense, in this article, we propose to focus on the specificity of an event: "the capacity to overflow" (Boullier 2010). An event is not just a "moment" or something which takes place in a specific time-place frame. It can be characterized by factors or elements (number of people, type of place, security arrangements, etc.) which "affect" its own nature as well as those individuals who become indirectly involved. This means the time-space of an event "overflows" its own boundaries. For example, a sport event is not only restricted to a stadium, it also affects the car traffic in a larger area, and the noise made by supporters can affect the residents near the stadium, etc. All these aspects of an event can be categorized in groups that we call "vectors of affectation" (Boullier 2010), and the success of an event depends on their regulation (by authorities, supporters, inhabitants, etc.). A vector can be considered as a flow which is circulating in a time-place and affects both the participants and nonparticipants of an event.

Applied to our subject, we question how these vectors can be expressed and regulated in a digital world. By inference, we can say that the success of an event in mixed reality depends on the "crossover" of the vectors between the virtual and physical worlds and how they can permeate each other.

In the first part, we will briefly present two cultural projects in mixed reality, a concert and an opera. This contextualization will allow us to clarify what we mean by "mixed reality". In fact, we will see that there is a range of possible definitions and visions to explain it. New practices are changing current definitions so we propose to present some new paradigms of mixed reality. The redefinition of these events and of mixed reality will require us to explain the approach and the methodology used. From this point, we can follow the timeframe to describe the sequence of the two events before concluding. 
2. Context: focus on two cultural events in mixed reality

\subsection{The Trans Musicales international festival}

In 2007 and 2008, the city of Rennes and the Trans Musicalest, an international festival of contemporary music, proposed concerts in mixed reality in order to allow people which were physically or virtually present, to share a common concert 1 . In 2007, the first prototype proposed a synchronized concert in real time between the concert hall of the festival and a dedicated digital space in Second Life+.w

Since its public launch in 2003, millions of users around the world have used Second Life + for education, art, science, teleconferencing, entertainment, business, and a multitude of other applications. SL is a persistent multiuser digital world accessible on the Internet, in which an individual can interact with the virtual environment and other users through their avatar. In addition, it allows synchronous and asynchronous communication through voice and text chat. We are particularly interested in this kind of virtual world because avatars can build their own 3D content from within the virtual world, that is why we consider Second Life + a "Virtual World of Content Creation" (VWCC)2 (Lucas 2012a).

In 2007, the audience (composed of thousands of people) in Rennes saw the avatars (70 people) in the digital world through a video stream (from SL) on a giant screen placed on the left 3 of the stage (Figure 1).

In Second Life+, avatars could watch the concert filmed in real time by a television crew. Most events like these only offer the possibility to watch a video stream. In order to have a new kind of interaction and experience in a virtual world (and more enjoyment for avatars in SL), some avatars played the role of musicians performing in the digital space. Even if the technology used did not allow the avatar musicians to imitate the movements of the group in Rennes, the avatars rehearsed choreographies during the previous weeks in order to perform a unique show in the digital world (Figure 2).

In 2008, the project of the Trans Musicales was reprised for three concerts. In addition, a series of mixed reality artist interviews and meetings between festival goers were established. In the physical realm, a camera captured visitors and there was a screen placed on a table that allowed them to see what was happening in the virtual world (Figure 3). The avatars in SL were also sitting around a virtual table where they could see a live video stream of the people in Rennes. As a result, the screen was a window between the two spaces and the table represented a bridge between participants, or as a "membrane" between the two worlds, if we desire to make an analogy with Castronova's term (Castronova 2005, p. 147).

The purpose of this type of configuration is to lessen the distance and create a portal for communication between the real and virtual worlds. It was through concerts, discussions, meetings, and interviews that people physically present and those who were far from Rennes were able to exchange and "literally relocate interactions between the Trans Musicales fans"4. 


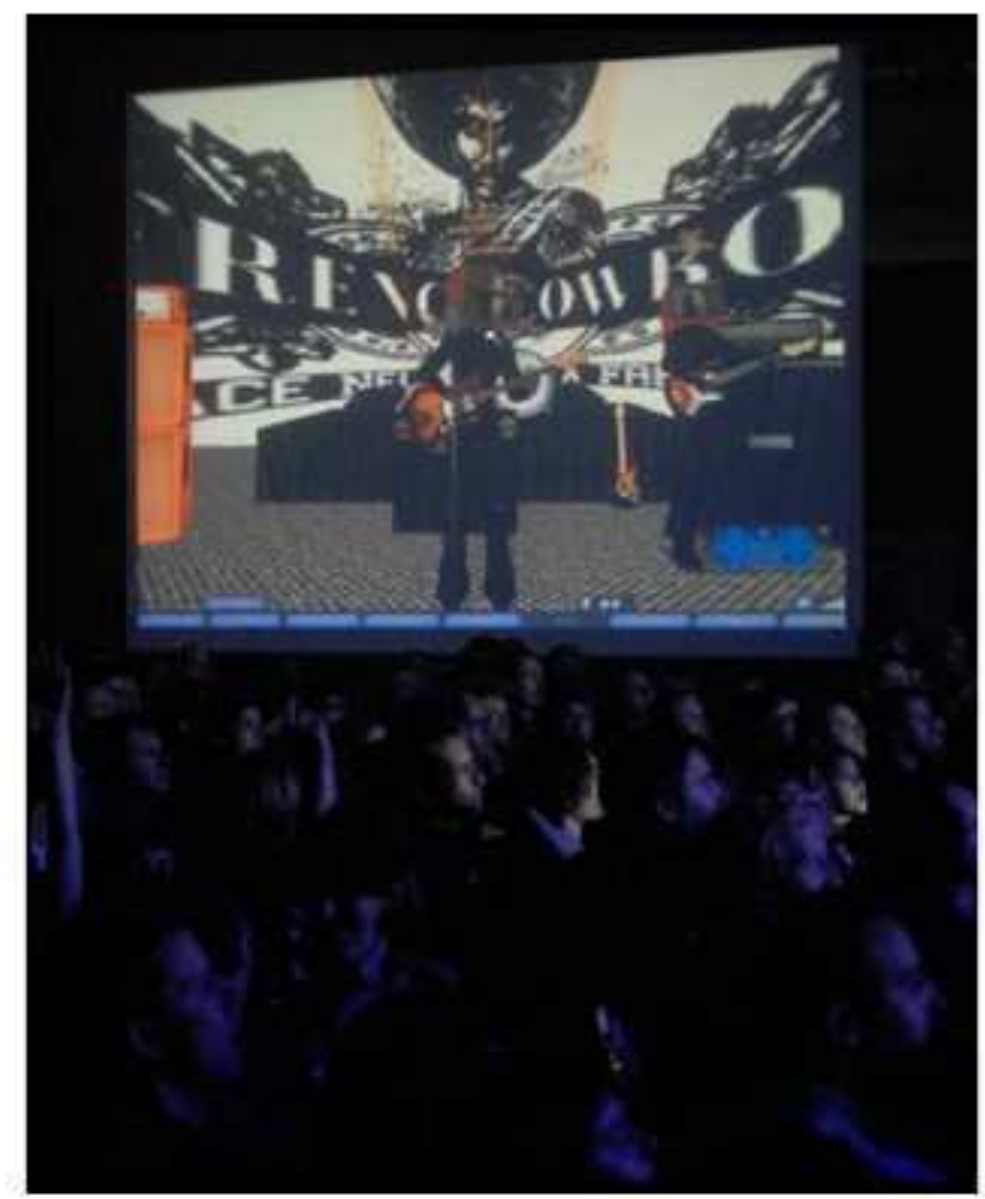

Figure 1. Concert in mixed reality. People in the concert hall can see avatars in Second Life + by a live stream*2007.

'raBis project2.2 The Ope

OperaBis5, which is managed by the Bibliotheque francophone du metavers6," was created to "unite a community of users, promote the French culture (including opera music) in foreign countries, but also on the French territory, in a process of cultural democratization" said Roger Folliard, the director of this association. The project team built a digital opera in Second Life+. The building in the virtual world is a realistic representation of the physical one. The architectural geometry of the concert hall was recreated, photographs of the building were imported as textures, and a screen was added to the digital stage in order to allow avatars to see live operas from the city of Rennes. Many projects like this one use Second Life+because of the potential to integrate various media (picture, video, and sound) and the malleability of the virtual world (the technical infrastructure). But, many of them just use the virtual world as a "second scene" or a stage which hosts productions that take place only in virtual worlds.7

However, since Second Life+ does not yet allow the hosting of hundreds of avatars in the same digital area, the creators of this project also created a second digital building in Open Sim + . This application is quite similar to Second Lifet, one difference being it is open source and it also has the 


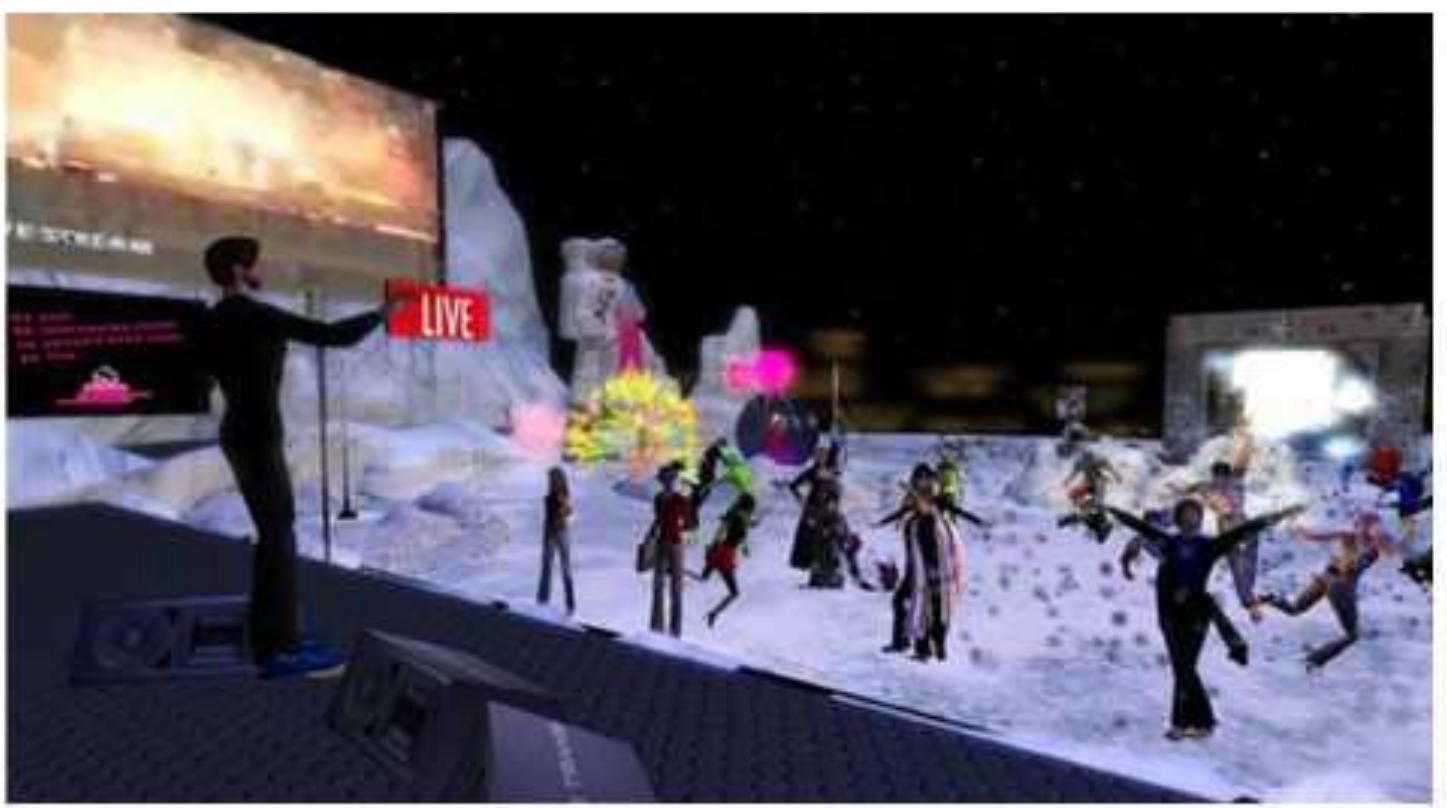

Figure 2. Concert in mixed reality. View in Second Life+: one avatar is the singer, other avatars are dancing. In the back, on the screen, the live stream from the concert hall*2008.

potential to scale as the number of users grows. In SL, it is also possible to copy an area (i.e. the "region" or the "island" in the SL language) in each virtual world to other areas in order to host more avatars. For the four performancess during the 2010 Á2011 season, it was also possible to access the event from other applications such as Francogrid +9 , Assemblive +10 , and Inworldz $\dagger 11$. Close to 300 avatars have witnessed these events in a virtual world (Figure 4).

In the opera, a control room mixed together the video streams from cameras that film the stage (for TV broadcast), and videos from the virtual world. During the performance "The Marriage of Figaro," there was a screen behind the stage to broadcast what the avatars were seeing from the virtual world. For the other performances of the OperaBis, the screen was removed' from the stage, but others were placed in the entrance hall, for example.

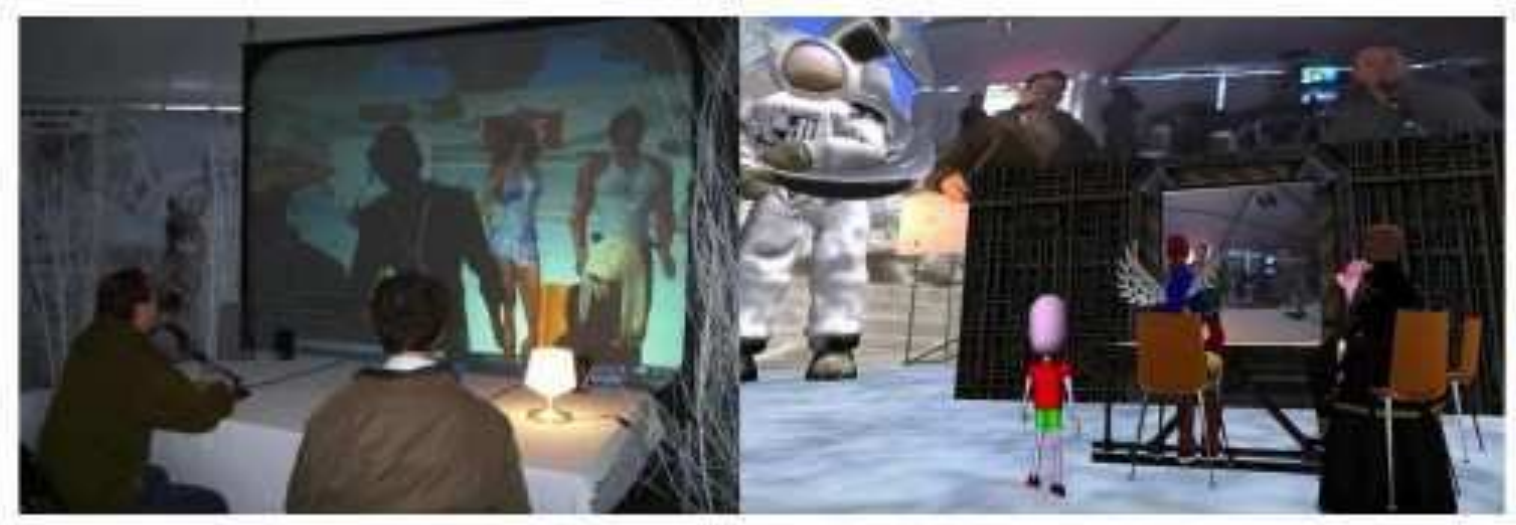

Figure 3. Discussion in mixed reality. Pictures are not corresponding but it is the same mixed reality space*2008. 




Figure 4. View in Second Life $+{ }^{*}$ Avatars see the opera through a live video stream. On stage, we can see the large black screen which is broadcasting both the physical actors and images from SL, which the real world audience sees.

\section{Rethinking mixed reality}

We consider an event and the process of mixed reality as concrete research objects. If we want to understand how their potential and their production can transform, translate, distort, and alter the meaning or the elements they are transporting (Latour 2007), we need to make a detour to understand the conceptual shift that these new forms of experiences in mixed reality can propose.

\subsection{From the continuum of reality to mixed reality}

Digital technologies have given rise to the conceptualization of a reality continuum. It is defined according to the degrees of virtuality that are "injected" into reality. For example, augmented reality (AR) consists of a layer of digital information (2D or 3D) integrated in real time with the physical world. AR can be applied to the visual perception, as well as to proprioceptive, tactile (Margolis et al. 2011), or auditory perceptions. One primary purpose of virtual reality (VR) is to create a simulation in which the individual is sensorially immersed according to and through the use of techniques and technologies (digital, mechanical, and physical installations). Often, VR is used to construct an environment that fosters a believable user experience. One of the first examples, which is also one of the most concrete, is the flight simulator. Ideally the pilot experiences a suspension of disbelief or at the very least is exposed to sensations and conditions similar to those in the "real world."

There are many other terms to describe the kinds of reality included in the continuum such as: 
. "artificial reality" (Krueger 1983)

. "altered reality" (Vanderheiden and Mendenhall 1994) in which some properties such as the time or the metric are changed

. "projected reality"

. "realistic reality" where the simulation resembles the real world as closely as possible

. diminished reality

. "augmented virtuality"

Of course, it is possible to discuss all of these definitions because they describe the interaction properties, technologies, and techniques used. However, their distinctions are not always explicit and are sometimes the result of marketing or artistic efforts in order to dissociate one form from another.

The concept of mixed reality was developed in 1994 by P. Milgram and A. F. Kishino as "... anywhere between the extrema of the virtuality continuum" and as "a particular subclass of VR related technologies that involve the merging of real and virtual worlds" (Milgram and Kishino 1994). For the authors, there are many intermediate states between the physical and virtual environments, and the continuum between these two ends is mixed reality. Unlike the definitions we mentioned here, mixed reality does not refer to a specific state or a specific device, but rather a range of possibilities. Other researchers have also worked on mixed reality (or forms of mixed reality) and focused on specific properties like the human experience (Robinett 1992), opportunities to "see the real, feel reality, and act on reality" (Sutherland 1965 ) or on corporeality, identity, and issues of geomatics (Bourassa and Edwards 2007).

\subsection{The new trends of mixed reality with virtual worlds}

When we talk about VR and AR, we generally make a connection to particular devices (glasses, sensors, smartphones, etc.). Mixed reality does not refer to a specific technology; it takes place in the intersection of the existing traditions and is defined by the results that its use allows. What is new in these projects is the use of "soft" spaces like Second Life+. Now it is possible to create a mixed reality portal in a wide variety of spaces, whereas early works were generally hosted in labs or art galleries.

This kind of mixed reality does not really invent a new kind of interaction because many previous projects in VR or artificial reality already proposed a Responsive Environment (Krueger 1983). But it is also important to note that it is not a simple act of communication between remote locations as with teleconferencing. Participants in a mixed reality engage with a physical world and virtual world to share an experience or an event. And, when it is a meeting with remote people, it is shared between the real world and a virtual world that is to say between "humans and avatars." This observation may seem trivial but we need to consider that the presence of an avatar is different 
to an encounter with another human (in terms of behavior, presence, interaction, etc.) 12 .

The goal of mixed reality is not the representation or the reading of the world or a part of the world, but its shared and distributed experience. To understand the issues of mixed reality, we must make a shift along the continuum of potentialities embedded in our realities, overcome the technical considerations, and understand that the composite arising from this hybridization is made of experiences, memories, and emotions. Milgram and Kishino's reality continuum takes on new meaning if we understand it as a possible composition of locations and interactions, not as any place that falls between the extremes of the continuum within virtuality. Mixed reality is a spatial composite made from the hybridization of a physical space and a digital space, not their addition or their superposition. As a result, the real world and virtual world are not the elements that invoke this hybridization, they are the foundation (Lucas 2012b).

\section{Position and methodology}

The previous section allows us to better understand the context in which devices can change the nature of an event and the relationships they convoke. Therefore, we must also consider the methodology to apply them because it concerns a distributed space, a hybrid space.

\subsection{Virtual and hybrid ethnographies}

Studying virtual worlds, or a subject that incorporates virtual worlds, raises a question about the position and methodology for researchers. For example, as Tom Boellstroff argues, it is possible "to treat Second Life as a cultureÁalbeit one that, like all cultures, has many subcultures within it" (Boellstroff 2010, p. 214). Moreover, we agree with Boellstroff who studies Second Life as selfcontained virtual spaces without really worrying about avatars and people's lives: "the notion of virtual worlds as social forms 'in themselves' is a fundamental theoretical conceit" of his book (Boellstroff 2010, p. 214). Boellstroff's approach helps us to understand that Second Life thas social forms which are governed by its own rules, laws and conventions, and its own economic regulations and policies.

Compared to Boellstroff's method which Brigitte Jordan qualifies as a "virtual ethnography," she proposes "hybrid ethnographies" (Jordan 2009, p. 185). "Interpolation of data gathered online and clarified or expanded offline has been shown to be highly productive and is probably the most commonly used methodology for the study of mixed, hybrid systems at this time" (Jordan 2009, p. 186). It tries to understand how digital practices fit into the daily lives of individuals and societies. "What constitutes a particular strength of hybrid studies is the combination of online observation and participation with offline interviewing of the participants" (Jordan 2009, p. 185). Generally, the clarification and the choice of methods are conducted 
to understand if we can apply the classical ethnographic methods in a virtual world. Specifically, the methodological debate is about the traditional concepts of anthropological ethnography which are "the field" and the "participant observation."

We believe that the two methods are legitimate and produce different approaches to articulate different arguments. Their uses depend on the context and the object studied and "the huge range of analytical themes and perspectives by which the online can be approached makes it virtually impossible to elaborate a methodology that could be employed widely in different online contexts" (Guimaraes 2005, p. 141). We recognize that, for our subject, hybrid ethnography appears to be a suitable match as we question the culture of events in mixed reality. There is, however, a semantic shift that we need to clarify. The goal of hybrid ethnographies is to "focus precisely on what virtual researchers ignore, namely the ways in which digital activities are embedded in people's daily lives, be that information seeking, blogging, emailing, or game playing" (Jordan 2009, p. 185). Our goal is not to understand how the practice of a virtual opera can change the life of a person. Our objective is to understand how the culture of the event can bleed back and forth in a mixed reality event. In other words, our focus is on the behavior and practices of people during the event in mixed reality to understand if a specific culture of the event is developed during its own production and exhibition.

\subsection{What is an event?}

Before describing the materials we use, we have to define how to characterize an event in order to understand how to study it. For Dominique Boullier, what makes the main feature of an event is its own capacity to spread, or to overflow out of its own time-space frame. For example, during a demonstration in the physical city (concert, game, street festival, etc.), some people may disrupt the habits of other individuals. "The noise, the density of passenger relations between them, everything is "affected" (Boullier 2010, p. 2). Especially in an urban setting, an overflow can take place in different ways. The crowd may dissipate in the streets in unexpected ways, in spite of security arrangements (police, security barriers, etc.) which strive to contain it. This same crowd can also affect people who do not participate in the event. In this sense, participants of an event can affect nonparticipants through different "vectors of affectation" (Boullier 2010, p. 45). These vectors may depend on the organization as well as other factors such as the participants, the security implementation, the location configuration, etc.

However, it is precisely this space left to an "overflow," this possibility of a "change," and finally the possibility of a "surprise" that characterizes the event and differentiates it from the ceremony (Boullier 2010, p. 4). By borrowing Sloterdijk's concept, Dominique Boullier discusses the "climate" of an event. For example, during a street event, it is expected that the climate of the street changes. The street changes its identity and appearance, i.e. it 
becomes "hot" or "festive." It is no longer a road anymore, but a place for pedestrians who make its codes and spaces their own. Therefore, if the "climate" is "hot" for many participants, it can be seen as a climate of insecurity for the others who are not participating in the festivities.

It should be worth noting that an event can also be characterized by the expectation it raises. The "affectedness" of the event concerns individual and collective feelings and passions, for example to see the band we love, the team we support, to laugh or cry with many people, etc. However, this aspect of an event falls outside of the parameters of the current discussion within this article.

For our part, in order to question the notion of hybridization and the concept of mixed reality, we will examine how the different audiences (the one in the real world and the one in the physical world) can affect each other through different "vectors" (Boullier et al. 2012).

\subsection{Materials used}

We worked with data from a variety of sources related to these events. The materials described and used are based on:

. participant observation. During the festival of Trans Musicales Rennes, we were present in the concert hall and in the virtual world. During the performances of the opera, we were present only in virtual worlds. . an official report about practices and uses of the OperaBis project.13' 1415

. images: from the official flickr gallery, from Picasa , images from flickr with tags like "operabis," "opera in SL," "opera in Second Life," images shared on blogs, etc., for a total around 400 pictures. For the Trans Musicales, we used personal pictures and few on the web. . blog posts (31 websites for the festival of the Trans Musicales16 and 39 websites for OperaBis).17'

\section{The event sequencing}

\subsection{Arrival and waiting: the conditioning}

Most often at the opera hall in Rennes, people arrive at the opera only a few minutes before the performance. They can choose to engage in discussions with friends in the hall or go directly to their seat. They are accompanied by ushers. At the Trans Musicales festival, the atmosphere is quite different. People arrive at the concerts depending on what they want to see (it is a festival so there are multiple stages and many performances). Some arrive when the doors open, nearly an hour before the first concert, to ensure good viewing as well as to get in the mood (they can dance, drink alcohol, etc.).

Whether it is an opera or a concert, there is preparation (or conditioning) leading up to the event. This can include an appropriate choice of clothing or 
listening to related music. We also know that the conditioning starts before the event in order to mobilize spirits (Boullier 2010, p. 57) through various communications, marketing, and community mobilization on the Internet (facebook, blogs, etc.). We know that "media contributes to produce the event [...] that is to say, to make it exist beyond the physical friction" (Boullier 2010, p. 50). Whether an event in the physical world or in the digital one, the "media plans" is quite similar, and this vector affects all people. Thus, the avatars receive notecards informing them of upcoming events. Blogs, email, and social networks also contribute to promote the events inworld and raise the expectations among participants.

For each of the concerts in mixed reality or for the opera performances, avatar organizers were present to inform and support the avatars. This had two goals. The first was to regulate the registration of avatars. A virtual world like Second Life+ can only support a certain number of avatars on each estate. That is why organizers set up registrations before each event. For each concert, avatars who were registered did not have the location of the stage, but a link (to teleport) that indicated the ticket office. From this spot, the organizers indicated a new teleport to go to the stage which was, in each case, located in the sky. This meant it was difficult to find the place if you are not familiar with the virtual world. This method is also used to protect the event venue against overcrowding. On the other hand, it is possible to imagine many devices that could be used to regulate avatars in the virtual world such as permits or automatic rights access. In the real world, the security arrangements also use many devices or mediators in addition to the police or security guards (video surveillance, safety barrier, etc.). But, the presence of the organizers, security guards, and policemen are the significance of a human authority. The "police vector" or "security vector" (Boullier 2010) is important to regulate and monitor the crowd involved in the event, but also to reassure those who do not participate. However, in a virtual world, the technical device occupies a prominent role; sometimes this can have some Big Brother appearances.

The second goal of this presence is to help the "newbies." 18 In this example, and for the project OperaBis, it was interesting to see that the' location of the final teleport was not directly in the event hall. In fact, during OperaBis, avatars were teleported to the front of the building. This implied' that they must enter the 3D building, open the doors, climb the stairs, and walk long corridors to finally find the entrance to the main room. The avatar had to make a journey before arriving at the hall. Once the avatars were in the room of the opera, other avatar organizers were there to help those who may have difficulty viewing the video stream or hearing the audio.19 It would certainly have been easier to give the landmark of the opera hall instead of a landmark which teleport avatars to front of the building. This approach, however, allowed the avatars to be conditioned for the event. We do not see this approach as a wish to copy the real world, but rather as a sign of the event culture. The journey is an essential spatial element of the event conditioning. The closer you arrive to the stage, the closer the show is to you. 
In this sense, as the media vector, the challenge of this spatial narrative architecture is to create expectation, i.e. desire.

In some ways, the preparation of the event is very similar from both sides of the membrane. Before the event, the media conditions and formats expectations, hopes and passions of the people interested in the event. For example, the surrounding hype (broadcast advertising, poster advertising, etc.) establishes a media vector that also affects people who are not directly connected to the event.

In both cases, when the time of the event started, individuals arrived early to take their seats. In both cases, they had to visit a ticket office to confirm their reservations or check for ticket availability. Staff organizers were available when the audiences needed information, but they were also there to regulate the crowd flow.

There were, however, points of difference. In Second Life, avatars can arrive late since the doors are always open. In addition, if they arrive too early, they do not have to wait in front of their computers, they can be "away from keyboard" (AFK). We know that some people are connected in Second Life + but can be engaged in other activities, such as phone calls, cooking, speaking with friends, etc. before and during the event. AFK is apparently a banal aspect of cybersociality but there are important theoretical implications for questions of place and time (Boellstroff 2010, p. 107). We do not develop this point in this article, but it will be certainly a good path to understand how the event can be lived differently: the user can be with friends behind the screen of his/her computer, he/she can surf on the web in the same time, chat on MSN, etc. In this sense, this participation mode can be certainly linked with the mode of "Hanging Out" describing the Web (Boyd 2008, Ito et al. 2010).

\subsection{During the event: the continuum control}

When the performance begins, silence reaches the different spaces, the different halls, the different worlds. When the lights go out in the hall of the opera, the sounds of voices go down and people speak in whispers. In the virtual world, avatars stop using voice chat, or they are told to stop. The public/open text chat (tchat) is still open, but avatars speak less. Here is a sample of the text chat in Second Life + at the beginning of one opera:

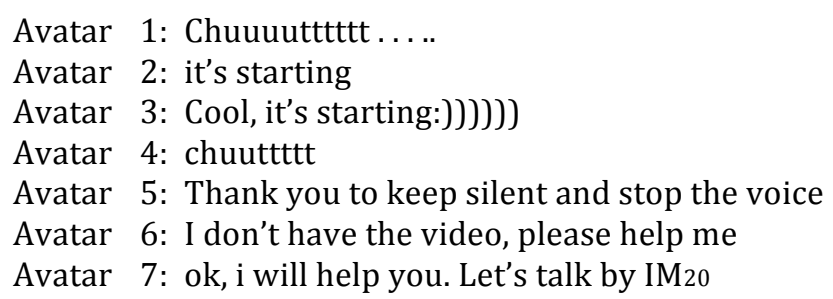

So, the shared audiences adapt and align themselves with the beginning of the event. In the digital world, avatars use text chat to speak about the quality 
of the stream and what they are feeling. The open tchat is a place for jovial comments while other messages can go through private channels. Unlike the public from the opera in Rennes, the exchange of messages on the public chat occurs "silently." In this sense, when an avatar says something in tchat, there is no interfering with close neighbors; there is no noise if we disregard the "visual noise."

Although first impressions may be that "the avatar's actions are the same as the people's in the physical world," we are in fact facing a new kind of event culture. While it is easy to talk and exchange with other people during a music concert (except for classical music perhaps), silence is customary during an opera. In the virtual world, avatars have the opportunity to share their impressions and opinions openly with the entire avatar audience throughout the performance. This "freedom" during performances also brings the potential for adverse effects on the event, because avatars who do not wish to participate in discussions are affected. As an event in the physical world, they can be affected by noise from other (visual noise or loud noise). But each avatar has the ability to close the chat and to cut the voice of the user of its choice (or for all other users). In this sense, the possible overflows remain confined to the world in which they occur, and the virtual world offers this particular feature to the user to control each vector since a control panel is the interface.

However, a few times, we observed the beginning of an overflow that could have affected the two worlds. First, the diffusion of a video stream from a virtual world placed just left of the stage affected the perception of the concert for the people in the hall. In order to regulate and secure the exchanges and interaction between the "real" and the "virtual" worlds, the organizers hid the SL public tchat from the screen. Furthermore, during the concerts in mixed reality, a video jockey (VJ) was mixing images from the live TV broadcast with videos from Second Life+. As a result, the organizers could change the video on the screen if problems arose. For example, a few times during the same concert, the Second Life+ server crashed. So, the organizers switched on the VJ's broadcast. During the same concert, an avatar started to protest against GMOs. To do so, he executed a script that launched "No-GMO" images throughout the space. One of the organizers identified who owned the objects, and attempted to speak with him. The organizer told the protester that the execution of this script was saturating the server and that it might produce a crash. Here, we have the demonstration of the police vector in order to regulate the traffic vector (or flow vector), that is to say the possibility for everyone to have a fluid experience. However, the organizers received no response from him. As organizers, a radical and technical solution could be to banish him, but the avatar stopped his scripts because other avatars asked him to do it. This form of community regulation is interesting, because the script triggered by this user affected all of the participants. It was a big problem for many of them (visibility, lag, etc.) and they were "not here to hear about that" said another one. This episode was not limited to the virtual world, because the audience in the hall could also 
see this protest. So, for the first time during these events, an overflow affected the two sides of the "membrane." It is an example of the capacity of avatars to affect the event through a diversion of attention.

Other "openings" to interaction and overflows have been made, but they were ephemeral. For example, during a concert, the singer in the hall said "Hello Second Life." Another example was during the OperaBis, when the' director of the opera delivered a first speech introduction to the public in the opera hall, left the scene, and delivered a second introduction speech to the public in the real world and the public in the virtual world with his avatar. These examples reflect attempts of interaction, but they were highly regulated.

\subsection{After the event: the decompression chamber}

At the end of events, whether concerts or operas, the public from every "world" applauded. In Second Life+, avatars thanked the artists by writing in the chat by performing gestures of appreciation.

At both the opera and concert, the audience gradually dissipated. Some people stayed in the hall while others left the building promptly. It is interesting to see that people who stayed in the performance space had the opportunity to discuss the event as part of their decompression. The goal of this time is to experience a transition, to not pass to another event (or another situation) too quickly. In Second Life+, some avatars log out immediately, others were teleported to another island to continue their activities while some stayed to discuss and share their feelings with a drink (Figure 5). After the performance of The Marriage of Figaro, they were invited to attend discussions with the director of the opera of Rennes and some of the artists.

During the Trans Musicales, the avatars continued to party with an exclusive concert in the virtual world. It was a way not to finish too quickly, to continue to party with friends and discuss the previous concert. Over time, the avatars logged out one by one. On both sides of the membrane, we

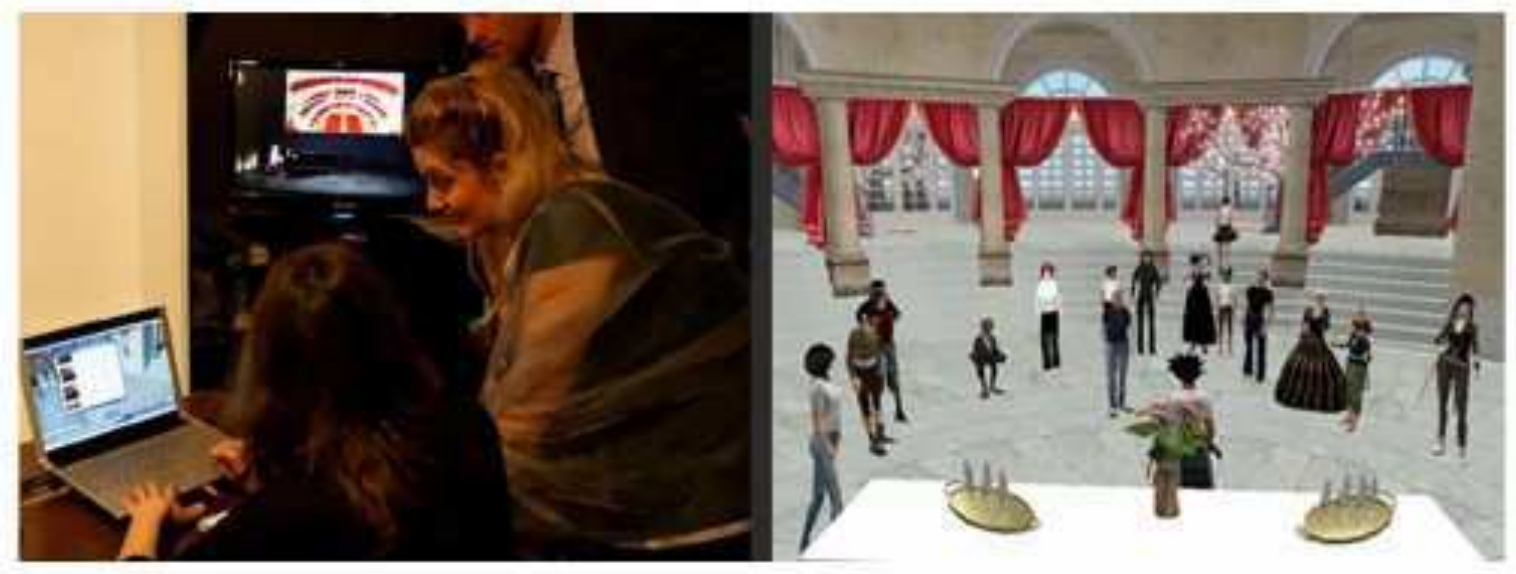

Figure 5. Actors and avatars share a drink at the end of the opera. 
can see the same behaviors. We did not observe any interactions at the conclusion of the event except for the exchanges between the artists and avatars described above. By contrast, the media vector continued to affect the audiences via the sharing of opinions, photos, videos, etc. onto social networks, blogs, newspapers, etc.

\section{Conclusion}

By describing the sequence of a concert and an opera, we have seen that an event in mixed reality remains close to what we know as a "classic event." In the real world, people are not really affected by the mixed reality configuration, 21 and in the virtual world, it seems avatars copy the practices from the real world. Indeed, interactions between the worlds are still limited.

However, we need to consider that all of the modifications we have presented, even if they are subtle, can influence the nature and perception of the event. Consider, for example, the fact that the artists in the real world attended talks with the virtual visitors after the performances. Also, the configuration of the event is modified when there is a large screen, projecting a stream from a virtual world at the back of the stage. It is clear that such projects will continue to be developed and that these emerging practices will continue to be shared and integrate the two worlds further. For now, we still have very little feedback from people who attend mixed reality performances from the real world perspective. Were they prepared to see images of Second Life + behind the actors during the performance? How did this experience really affect them?

We already see the emergence of projects in which avatars can change the ambiance of the real world and people in the physical place can change the architecture and the ambiance of the digital area.22 Many forms of interaction between artists and mixed audiences can be further developed. With more interactions, perhaps we will see, for example, an erosion of the AFK culture in virtual worlds. However, if we want to see new interactions occur, if we want to have a real mixed reality event, we need to find the right balance between vector management and overflows. The nature and the culture of events is to overflow, but the risk for events in mixed reality is to over-regulate them (digital technologies allow control of different vectors of affectation in many ways), thereby limiting people to be passive members of the audience. We know that "overflows are the antithesis of the frame of the event, and the sign of a form of failure of the containment, but they also manifest its existence" 23 (Boullier 2010, p. 128). Conventionally, organizers and artists desire control over an event. The desire for mixed reality events is that people on both sides of the membrane can have the capacity to affect each other since the vectors of affectation need to circulate bidirectionally to manifest the event.

Finally, the next major challenge for these kinds of events will be to regulate the "cohabitation vector." That is to say, the vector that manages the convergence of audiences as they all participate in live events. If we 
understand this dynamic, we will see that activities from one side of the digital membrane may organically flow to the other as if by osmosis.

\section{Notes}

[1] Website of the project in mixed reality: http://trans2008.blogspot.com.

[2] In French: "Monde Virtuel de Creation de Contenus" (MVCC).'

[3] In 2007, the giant screen was on the left, in 2008 it was on the right.

[4] "ProjetTransmusicalesRealites Mixtes": http://bit.ly/rm00aR' '

[5] Website of the OperaBis: http://operabis.net/le-projet-operabis'

[6] Presentation of the association: http://www.bibliotheque-francophone.org/2005/04/quisommes-nous.html As the SL Shakespeare Company (SLSC) for example: http://mshakespeare.com.

[7] Unfortunately, this remarkable initiative will go down on 29 October or thereabouts: http://twelfthnight.mshakespeare.com/blog 6 September 2010: Rita, or The Beaten Husband, Gaetano Donizetti; 6 January 2011: The Marriage of Figaro, Wolfgang Amadeus Mozart; 6 April 2011: Eugene Onegin,

[8] Pyotr Tchaikovsky; 3 June 2011: The Abduction from the Seraglio, Wolfgang Amadeus Mozart.

Francogrid is a French open metaverse: http://francogrid.org Assemblive website: http://www.assemblive.com Inworldz website: http://inworldz.com

[9] About these researches, you can see publications of the Virtual Human Interaction Lab of

[10] the Stranford University: http://vhil.stanford.edu/pubs/

[11] OperaBis report (in French): Suivi des publics et analyse des usages. "Projet service'

[12] numeriqueculturelinnovant 2010": http://bit.ly/rK8nZT'

OperaBis official gallery: http://www.flickr.com/photos/49301351@N06 https://picasaweb.google.com/moiraudjp/OperabisMozart

[13] List made in 2008 after the end of the project. See page 31 Á36 in the official report mentioned above.

[14] Newbie: "A newcomer to Second Life or Teen Second Life; a Resident who has joined for

[15] a relatively short period of time and/or is not familiar or comfortable with Second Life's

[16] culture, interface etc." Definition from the Second Life+Wiki: http://wiki.secondlife.com/

[17] wiki/Newbie

[18] Many discussions were about technical issues such as the hardware or the version of the viewer, and so on.

IM means instant message. It's a private message that avatars can be exchanged between them. The other avatars can see it.

During the Trans Musicales, many people who were in the hall did not understand that the broadcast was from Second Life+. They thought it was a record video.

[19] The project Disorder Screen Control was a teleperformance that gathered individuals in Second Life and the people who were at the Discontrol Party in Paris. This initiative took

[20] place during the festival Futur en Seine in Paris. Using text messaging, Second Life + avatars could control two agents with spy cameras who had infiltrated the party. These agents became the physical avatars of the virtual avatars. During the event, the

[21] architecture and the animations on the walls and on the floors in the virtual world changed according to the pulse of the physical world. In this case, the digital world has

[22] "listened" to the physical world but this could be inverted and each world could listen and affect the other. Presentation of Discorder Screen Control: http://ener.ensad.fr/disorderscreen-control 
[23] In French in the text: "Les debordementssontl'antithese du cadrage, et le signed'une-” formed'echec du contenant, maisilsmanifestent en meme temps son existence"."^ 
Boellstroff T., 2010, Coming of Age in Second Life, An Anthropologist Explores the Virtually Human, Princeton University Press, seventh printing and first paperback edition.

Boullier D., 2010, La ville événement, Foules et publics urbains, La ville en débat, PUF

Boullier D., Chevrier, S., Juguet, S., 2012, Événements et sécurité. Les professionnels des climats urbains, Paris: Les Presses des Mines

Bourassa R., Edwards G., « La réalité mixte, les mondes virtuels et la géomatique : de nouveaux enjeux », Actes du colloque Géocongrès International, « Histoire de voir le monde », Québec, 2-5, octobre 2007

Boyd, D.M., 2008. “Taken Out of Context: American Teen Sociality in Networked Publics." PhD Dissertation, School of Information, University of Califonia, Berkeley.

Castronova E., 2005, Synthetic Worlds, University of Chicago Press.

Guattari F., Rolnik S., 2008, Molecular Revolution in Brazil, Translated by Karel Clapshow and Brian Holmes, Semiotext(e)

Ito, M., Baumer, S., Bittanti, M., Boyd, D., Cody, R., et al., Hanging Out, Messing Around, and Geeking Out: Kids Living and Learning with New Media, The MIT Press Cambridge, Massachusetts London, England, 2010

Jordan B., Blurring Boundaries: The "Real" and the "Virtual" in Hybrid Spaces, Human Organization; Summer 2009; 68, 2; ABI/INFORM Global pg. 181

Krueger M., 1983, Artificial Reality, Reading, Mass., Addison-Wesley

Latour B., 2007, Changer de société, refaire de la sociologie, Paris, La Découverte.

Lucas J.-F., 2012a, "La ville numérique et ses avatars dans les mondes virtuels" in Perény E., AmatoE. A., L'avatar numérique et ses mondes simulés, Hermès Science Publications, Collection Information, Hypermédias et Communication, (to be published).

Lucas J.-F, 2012b, "Interactions et réalité mixte dans la ville hybride”, Actes de colloque HyperUrbain.3, Europia Productions (to be published).

Margolis T., DeFanti T., Dawe G., Prudhomme A., Schulze J., Cutchin S., 2011, "Low cost heads-up virtual reality (HUVR) with optical tracking and haptic feedback", In Proceedings of SPIE Vol. 7864

Mário J. L., Guimarães Jr., 2005, "Doing Anthropology in Cyberspace: Fieldwork Boundaries and Social Environments", in Hine C., Virtual Methods Issues in Social Research on the Internet, Berg Publishers

Milgram P., Kishino A.-F., 1994, Taxonomy of Mixed Reality Visual Displays IEICE. Transactions on Information and Systems, E77-D(12), pp. 1321-1329

Robinett W., 1992, Synthetic Experience: A Proposed Taxonomy, Presence, Vol. 1, No. 2.

Sutherland, I. E., 1965, The ultimate display, Proceedings of the IFIPS Congress, 2, p.506-508

Vanderheiden, G. and Mendenhall, J., 1994, Use of a two-class model to analyse applications and barriers to the use of virtual reality by people with disabilities, Presence, The MIT Press 